
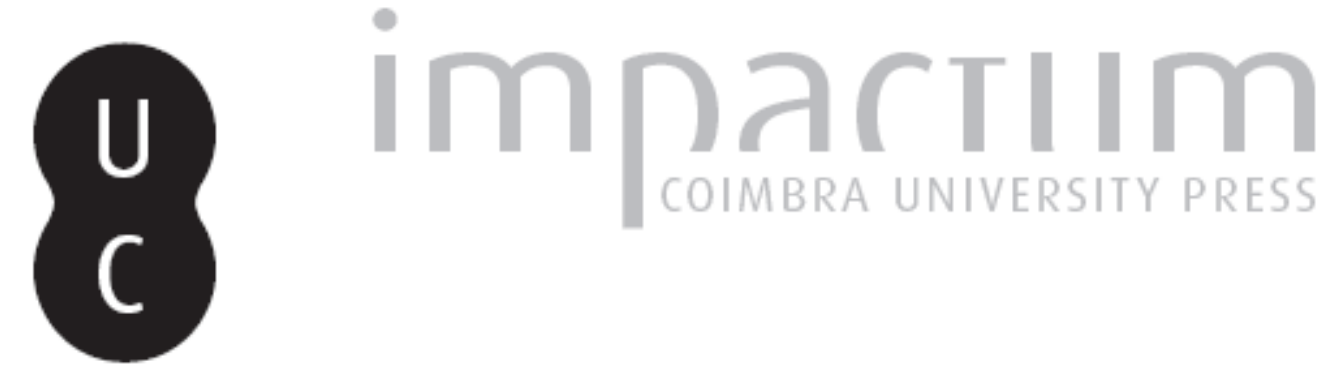

50 anos de legislação farmacêutica na Europa (1965-2015): o caso específico da AIM

Autor(es): $\quad$ Sousa, Micaela Figueira de; Pita, João Rui; Pereira, Ana Leonor

Publicado por: Centro de Informação Europe Direct de Aveiro; Centro de Estudos

URL

persistente: Interdisciplinares do Século XX

DOI:

URI:http://hdl.handle.net/10316.2/39349

Accessed : $\quad$ 26-Apr-2023 14:12:30

A navegação consulta e descarregamento dos títulos inseridos nas Bibliotecas Digitais UC Digitalis, UC Pombalina e UC Impactum, pressupõem a aceitação plena e sem reservas dos Termos e Condições de Uso destas Bibliotecas Digitais, disponíveis em https://digitalis.uc.pt/pt-pt/termos.

Conforme exposto nos referidos Termos e Condições de Uso, o descarregamento de títulos de acesso restrito requer uma licença válida de autorização devendo o utilizador aceder ao(s) documento(s) a partir de um endereço de IP da instituição detentora da supramencionada licença.

Ao utilizador é apenas permitido o descarregamento para uso pessoal, pelo que o emprego do(s) título(s) descarregado(s) para outro fim, designadamente comercial, carece de autorização do respetivo autor ou editor da obra.

Na medida em que todas as obras da UC Digitalis se encontram protegidas pelo Código do Direito de Autor e Direitos Conexos e demais legislação aplicável, toda a cópia, parcial ou total, deste documento, nos casos em que é legalmente admitida, deverá conter ou fazer-se acompanhar por este aviso.

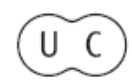


DEBATER

A EUROPA

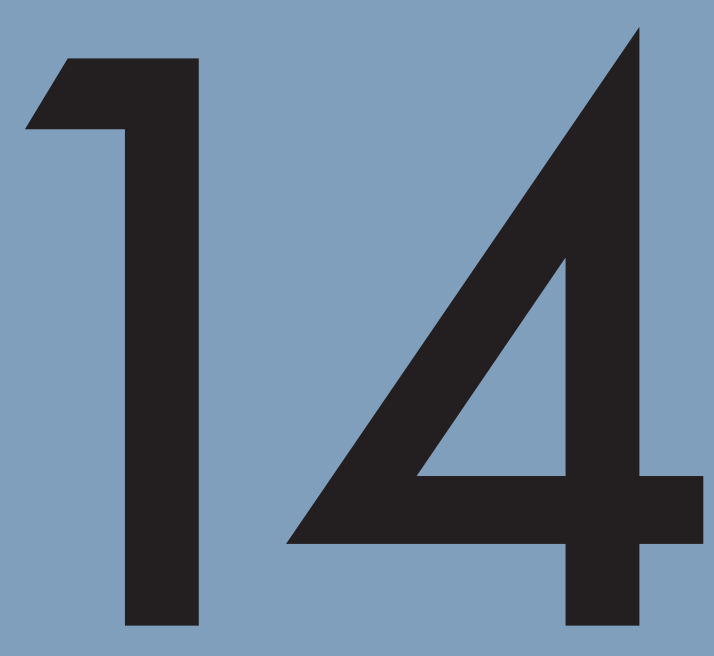

jan-jun 2016

EUROPA, FARMÁCIA, MEDICAMENTOS

EUROPE, PHARMACY, MEDICINES 


\title{
50 anos de legislação farmacêutica na Europa (1965 - 2015). O caso específico de AIM
}

\author{
Micaela Figueira de Sousa \\ Doutoranda FFUC; CEIS20-Universidade de Coimbra, Portugal \\ E-mail: micaela.sousa@gmail.com \\ João Rui Pita \\ Professor da FFUC; CEIS20-Universidade de Coimbra, Portugal \\ E-mail:jrpita@ci.uc.pt \\ Professora da FLUC; CEIS20-Universidade de Coimbra, Portugal \\ E-mail: aleop@ci.uc.pt
}

\section{Resumo}

A história da Europa do Medicamento partilha da ideia geral de construção e integração europeias, com as necessárias adaptações decorrentes da ambiguidade do medicamento enquanto mercadoria e produto de saúde. Neste estudo procuramos fazer um histórico da legislação comunitária em matéria de medicamentos, tomando como elemento central de análise a autorização de comercialização. A Europa do Medicamento começa a desenhar-se em 1965 com a publicação da Diretiva 65/65/CEE e evoluiu paulatinamente até hoje, tendo como grande objetivo a implementação do Mercado Único de medicamentos, sem esquecer a defesa da Saúde Pública e os interesses dos consumidores.

Palavras-chave: Legislação Farmacêutica; Europa do Medicamento; Regulação Farmacêutica; AIM; História da Farmácia 


\begin{abstract}
The history of European Union Pharmaceutical Legislation shares the general European ideal of integration and development, with the required adaptations stemming from the ambiguity of medicines as goods and health products. In this study we intend to produce a history of the European law in terms of pharmaceuticals, with the core analytical theme being the marketing authorization application (MAA). The EU Pharmaceutical Legislation emerged in 1965 with the publishing of the Council Directive 65/65/CEE and evolved gradually until today, having as its main goal the implementation of a single market, the protection of Public Health and the best interest of the consumers.
\end{abstract}

Keywords: Pharmaceutical Law; Medicines Regulation; Marketing Authorization Application; History of Pharmacy

\title{
Introdução
}

A construção da Europa do Medicamento e a gradual consolidação do estatuto jurídico do medicamento a nível europeu partilham da ideia geral de construção e integração europeias, com as necessárias adaptações decorrentes da ambiguidade do medicamento enquanto mercadoria e produto de saúde. Se por um lado o medicamento representa, para a União Europeia $(\mathrm{UE})^{1}$, uma mercadoria, e portanto o objetivo comunitário passa, também nesta área, pelo estabelecimento do Mercado Único, por outro lado é um produto de saúde com elevado peso na balança económica da comunidade e um importante instrumento de defesa da Saúde Pública e dos mecanismos de segurança social e dos serviços de saúde, cujas administração e jurisprudência estão, à luz dos Tratados europeus, sob a responsabilidade dos Estados membros. Isto, mesmo depois da extensão das responsabilidades da UE no que respeita à defesa da Saúde Pública, feita pelo Tratado da União Europeia ${ }^{2}$, também conhecido por Tratado de Maastricht.

\footnotetext{
${ }^{1}$ A criação da União Europeia remonta a 1992 como resultado da assinatura do Tratado de Maastricht Tratado da União Europeia que veio preparar a então Comunidade Económica Europeia (CEE) para a união monetária e introduzir elementos fundamentais à execução de uma união política. A partir daqui utilizaremos esta designação, sempre que nos referirmos à CEE.

${ }^{2}$ Tratado da União Europeia, assinado em Maastricht em 7 de fevereiro de 1992. JO n ${ }^{\circ}$ C191, de 29 de julho de 1992.
} 
Isto faz com que, em questões basilares da política do medicamento, como são a fixação dos preços e o estabelecimento e inclusão nos regimes de comparticipação, a harmonização legislativa tenha sido muito limitada ${ }^{3}$. E isto acontece desde logo porque os Estados membros não estão dispostos a perder a autonomia de decisão e a ceder as suas competências individuais no estabelecimento de políticas nesta área. A UE aplica assim o Princípio de Subsidiariedade que deixa à competência individual dos Estados membros matérias como a definição da política de saúde e especificamente a fixação de preços de medicamentos e a sua inclusão nos sistemas de segurança social ${ }^{4}$.

Ou seja, apesar de a regulação do medicamento ser um processo altamente dinâmico e complexo, talvez das matérias mais reguladas pelos Estados desenvolvidos, e que vai desde a Investigação e Desenvolvimento (I\&D) à dispensa e utilização, passando pela produção e comercialização, a verdade é que apenas uma parte da regulação do medicamento encontrou lugar na legislação europeia. Podemos, portanto, afirmar que o Mercado Único e a livre circulação de medicamentos ao nível da UE ainda hoje não são uma realidade plena ${ }^{5}$.

É importante referir que quando se fala de um Mercado Único de medicamentos na UE não significa que todos os medicamentos devam estar disponíveis em todos os mercados comunitários. Até porque cada um dos mercados tem as suas especificidades e tradições médicas que não justificam a comercialização de determinados medicamentos em determinados mercados. A existência de um Mercado Único de

\footnotetext{
${ }^{3}$ Feick atribui o sucesso da Europa do Medicamento precisamente ao facto de as questões políticas e económicas do medicamento não estarem sob a esfera de ação da comunidade. Cf. FEICK, Jürgen "Marketing authorization for pharmaceuticals in the European Union. How regulators in energy, financial services, pharmaceuticals and telecoms are coming together in european networks and agencies. " In European Policy Forum. Joining-up Europe's Regulators. London, 2008. p. 35-64.

${ }^{4}$ Cf. MCKEE, Martin; MOSSIALOS, Elias - Health policy and European law: Closing the gaps. Public Health. 120 (2006), p.16-22. Neste artigo os autores explicam os paradoxos existentes na política de saúde comunitária e de que forma a UE tem lidado com o problema, à luz dos seus Tratados. Se por um lado os sistemas de saúde europeus são diversos e respeitam diferentes tradições e modelos, estando alheios à jurisprudência comunitária, a verdade é que a maior parte dos seus elementos constitutivos e muitos dos seus objetivos encontram lugar no direito comunitário. Ver também PEREIRA, André Gonçalo Dias - Um direito da saúde para a europa? Debater a Europa. 2/3, janeiro/dezembro (2010), p.25-37.; JARDIM, Sara Vera - Saúde Pública made in União Europeia. Base legal habilitadora e limites da competência europeia em matéria de Saúde Pública (artigo $152^{\circ}$ do TCE). Lex Medicinae. Revista Portuguesa de Direito da Saúde. Ano 6: 11 (2009), p.67-94.

${ }^{5}$ Cf. PERMANAND, Govin; ALTENSTETTER, Christa - "The politics of pharmaceuticals in the European Union" In Mossialos, Elias, [et al.]. Regulating pharmaceuticals in Europe: striving for efficency, equity and quality. Berkshire: Open University Press - McGraw-Hill Education, 2004. p. 3854. ; VALVERDE, José Luís - "El estatuto jurídico del medicamento en la unión europea" In Ministerio de Sanidad y Consumo. España y Europa, hacia un ideal sanitario común. Madrid, 2002. p. 85-165.
} 
medicamentos pressupõe sim, a eliminação de barreiras ao mercado intracomunitário, nomeadamente ao nível da fiscalidade e dos procedimentos técnico-científicos ${ }^{6}$.

Para este estudo consideramos a história da Europa do Medicamento dividida em três grandes fases. A $1^{\text {a }}$ fase corresponde ao período entre 1965 e 1993. Escolheu-se esta cronologia porque 1965 foi o ano de publicação da primeira diretiva relativa a especialidades farmacêuticas e 1993, o ano em que se começa a desenhar, na prática, uma nova estrutura de avaliação de medicamentos a nível europeu, ao mesmo tempo que se começam a levantar novos desafios. Esta $1^{\text {a }}$ fase caracterizou-se inicialmente pela harmonização técnica (procedimentos) e científica com o grande objetivo de estabelecer um Mercado Único de medicamentos, procedendo deste modo ao que Broscheid e Feick definem como "europeização de nível nacional", uma vez que no que respeita à tomada de decisão de comercialização de medicamentos, o poder estava nas mãos dos Estados membros.

A $2^{\text {a }}$ fase corresponde ao período entre 1995 e 2001, em que se implementa e consolida um verdadeiro Sistema Europeu de Avaliação e Autorização de medicamentos. Esta fase caracterizou-se pela institucionalização europeia em matéria de avaliação de medicamentos, pela transferência do poder de decisão de um nível estritamente nacional para um nível supranacional, pela revisão do modelo europeu de avaliação de medicamentos e por uma maior preocupação para com a defesa da Saúde Pública e os interesses dos consumidores - "europeização de nível europeu”"9.

\footnotetext{
${ }^{6}$ Feick, Jürgen - "Marketing authorization for pharmaceuticals in the European Union. How regulators in energy, financial services, pharmaceuticals and telecoms are coming together in european networks and agencies. " op. cit. p.42.

${ }^{7}$ BROSCHEID, Andreas; FEICK, Jürgen- Towards a European FDA? The review of European pharmaceuticals authorization. Prepared for delivery at the 2005 Meeting of the European Union Studies Association, March 31 - April 2, Austin, Tx., 2005. p.8. Expressão traduzida pelos autores.

${ }^{8}$ Esta nova visão da Europa do Medicamento resultou necessariamente das políticas e das estratégias europeias em vigor. A partir dos anos 90, com a assinatura do Tratado de Maastricht (1992) e do Tratado de Amesterdão (1997), a Europa deixa a dimensão exclusivamente económica para se preocupar com questões relacionadas com a defesa da Saúde Pública, do ambiente e dos interesses dos consumidores. Isto apesar de, no que respeita à Saúde Pública, o fazer de forma muito limitada. A proteção da saúde humana foi desde logo introduzida nos Tratados Europeus pelo Tratado de Maastricht. O então adicionado "Título X - A Saúde Pública" instituía expressamente no art. $129^{\circ}$ que: "A Comunidade contribuirá para assegurar um elevado nível de protecção da saúde humana, incentivando a cooperação entre os Estados-membros e, se necessário, apoiando a sua acção.”. A proteção dos consumidores foi por sua vez introduzida pelo "Título XI - A Defesa dos Consumidores", art. ${ }^{\circ} 129^{\circ}$-A. O objetivo passava por promover, não só a saúde dos consumidores, mas também a segurança e os interesses económicos e jurídicos, realizando neste âmbito uma ação de apoio às políticas desenvolvidas pelos Estados-membros. Todas estas políticas foram mais tarde continuadas e desenvolvidas no Tratado de Amesterdão, passando o art. $^{\circ} 129^{\circ}$ a ter a seguinte redação: “1. Na definição e execução de todas as políticas e acções da Comunidade será assegurado um elevado nível de protecção da saúde.”, reforçando a política europeia em matéria de Saúde Pública, mas mantendo-se fiel ao Princípio de Subsidiariedade: "5. A acção da
} 
A $3^{\text {a }}$ fase começa a estruturar-se no início do século XXI, fruto da profunda revisão do Sistema Europeu de Avaliação e Autorização de medicamentos, da evolução técnico-científica ao nível da medicina e do medicamento em particular, mas também das políticas europeias em matéria de competitividade assente no conhecimento (Conselho Europeu de Lisboa 2002).

Esta fase, onde nos encontramos atualmente, caracteriza-se por uma nova dinâmica de avaliação de medicamentos, mas também por uma maior preocupação com matérias como a inovação e competitividade da Indústria Farmacêutica europeia, a regulação dos medicamentos órfãos, dos medicamentos pediátricos e da vigilância póscomercialização - Farmacovigilância, entre muitas outras.

Se até aqui a avaliação de medicamentos a nível europeu se baseava na tríade qualidade, segurança e eficácia, a partir de aqui novos desafios se levantam decorrentes não só da evolução técnico-científica, mas também da limitação de recursos financeiros, ao nível dos sistemas de saúde dos Estados membros, e da necessidade de incentivar o desenvolvimento e sustentabilidade da Indústria Farmacêutica europeia que nas últimas décadas vem perdendo terreno em relação à sua congénere norte americana. A política industrial da UE relativamente à Indústria Farmacêutica tem assim como grande objetivo promover a competitividade e a inovação.

A regulação da autorização de comercialização de medicamentos tem por isso neste âmbito seguido dois grandes princípios. Por um lado pretende proporcionar um mercado alargado, com as vantagens económicas daí decorrentes. Por outro lado, ao racionalizar os procedimentos de avaliação pretende reduzir os custos para as empresas, criando assim um ambiente favorável à I\&D e à produção de medicamentos na Europa.

Nas palavras da Comissão Europeia as políticas empreendidas nesta área não devem, no entanto, perder de vista o objetivo último de promoção e proteção da Saúde Pública. No entanto, alguns autores defendem que se assiste nas últimas décadas a uma clara tendência para uma maior proteção dos interesses económicos da Indústria

Comunidade no domínio da saúde pública respeitará plenamente as competências dos Estados-membros em matéria de organização e prestação de serviços de saúde e de cuidados médicos.(...)" (TCE, art. ${ }^{\circ} 152^{\circ}$, atual TFUE, art. ${ }^{\circ} 168^{\circ}$ ). A defesa dos consumidores, plasmada no anterior art. ${ }^{\circ} 129^{\circ}$-A, foi também desenvolvida no Tratado de Amesterdão, denotando-se uma particular preocupação para com a informação e educação dos cidadãos europeus (TCE, art. $^{\circ} 153^{\circ}$ )

${ }^{9}$ BROSCHEID, Andreas; FEICK, Jürgen - Towards a European FDA? op cit. p.8. Expressão traduzida pelos autores. 
Farmacêutica, em detrimento da defesa da Saúde Pública ${ }^{10}$. Entendem estes autores que esta política protecionista está especialmente patente na evolução do procedimento de avaliação verdadeiramente comunitário, o Procedimento Centralizado. Apesar de não ser nosso objetivo para este trabalho estudar a influência da Indústria Farmacêutica e a captura do sistema por este grupo económico, a verdade é que não podemos deixar de referir que na nossa opinião, a integração europeia no que diz respeito à avaliação de medicamentos não tem posto em causa a defesa da Saúde Pública. Pode não ser o seu grande objetivo, no nosso entender o grande objetivo passa e sempre passou pelo estabelecimento do Mercado Único, ou seja, um objetivo económico, mas não tem descurado a dimensão sanitária do medicamento. Desde logo pelo facto de desde a sua implementação não ter havido nenhuma crise de confiança no sistema provocada por um acidente tóxico grave com medicamento, mas também pelas políticas traçadas nas últimas décadas com especial atenção para a defesa da Saúde Pública, para a proteção e promoção da saúde humana.

Para esta análise centrámo-nos especificamente nos procedimentos de autorização de introdução no mercado (AIM) de medicamentos de uso humano, deixando de lado a análise aprofundada de outras questões igualmente importantes e interdependentes, como sejam a regulamentação do fabrico, da distribuição, dos mecanismos de vigilância pós-comercialização - Farmacovigilância - e da publicidade a medicamentos, entre outras matérias. Referimo-nos a estas questões apenas pontualmente e contextualizando-as com as medidas tomadas ao nível da regulamentação da autorização de comercialização de medicamentos.

O objetivo do estudo passou assim pela descrição e análise da evolução do estatuto jurídico do medicamento, com base nos procedimentos de AIM, procurando contextualizá-la com a política europeia em matéria de medicamentos e as suas linhas orientadoras.

\footnotetext{
${ }^{10}$ Cf. ABRAHAM, John - The pharmaceutical industry as a political player. The Lancet. 360: novembro, 9 (2002), p.1498-1502.; ABRAHAM, John - Partial Progress: Governing the Pharmaceutical Industry and the NHS, 1948-2008. Journal of Health Politics, Policy and Law. 34: 6 (2009), p.931-977.; COURTNEY DAVIS, John Abraham - The political dynamics of citizenship, innovation, and regulation in pharmaceutical governance. Innovation: The European Journal of Social Science Research. 25: 4 (2012), p.478-496.; LEWIS, Graham; ABRAHAM, John - The creation of neo-liberal corporate bias in transnational medicine control: The industrial shaping and interest dynamics of the European regulatory state. European Journal of Political Research. 39 (2001), p.53-80. ; KRAPOHL, Sebastian Thalidomide, BSE and the single market: An historical-institutionalist approach to regulatory regimes in the European Union. Ibid.46 (2007), p.25-46.
} 
A evolução da regulação dos procedimentos de autorização de comercialização de medicamentos a nível europeu tem encontrado algumas barreiras, pois tem de responder a questões complexas do ponto de vista jurídico e defender interesses muito diversos e até mesmo opostos. Se por um lado deve impedir a comercialização de medicamentos de qualidade inferior, com efeitos adversos inaceitáveis para a patologia em questão e sem eficácia terapêutica demonstrada, por outro lado deve garantir a disponibilização no mercado de medicamentos inovadores, de eficácia terapêutica reconhecida, o mais rapidamente possível.

Já a criação do Mercado Único de medicamentos deve ser vista sob dois pontos de vista diferentes, mas ambos importantes. Do ponto de vista da Indústria Farmacêutica o Mercado Único significa o acesso a um mercado alargado, representado pelos mercados dos vários Estados membros. Do ponto de vista dos consumidores significa igual acesso a todos os medicamentos disponibilizados na UE.

Por todos estes motivos, a europeização dos procedimentos de autorização de medicamentos, apesar de ser um caso de sucesso $^{11}$, teve de atingir um equilíbrio nem sempre fácil e a sua história demonstra bem a dificuldade em alcançar os objetivos inicialmente traçados.

\section{A 1 a fase da Europa do Medicamento (1965-1990). Harmonização} administrativa e técnico-científica.

Quando olhamos para a história da regulação do medicamento na maior parte dos países industrializados, concluímos que a maioria dos sistemas reguladores surgiu como consequência de acidentes tóxicos provocados por medicamentos. Foi assim nos Estados Unidos da América (EUA) quando em 1937 o desastre da sulfonamida despertou para a necessidade de estabelecer normas de regulação sobre os medicamentos e levou à publicação do Federal Food, Drug and Cosmetic Act em 1938. Com a publicação deste diploma os medicamentos passaram a ter de fazer provas de segurança antes de serem introduzidos no mercado.

\footnotetext{
${ }^{11}$ Cf. KRAPOHL, Sebastian - Credible Commitment in Non-Independent Regulatory Agencies: A Comparative Analysis of the European Agencies for Pharmaceuticals and Foodstuffs. European Law Journal. 10: 5, setembro (2004), p.518-538. ; KRAPOHL, Sebastian - Thalidomide, BSE and the single market: An historical-institutionalist approach to regulatory regimes in the European Union. op. cit.
} 
Também em Portugal assistimos, na década de 50, a um importante ponto de viragem na regulação do medicamento. $\mathrm{O}$ caso Lipocina, um acidente tóxico provocado por um medicamento antibiótico, ocorrido no Fundão em 1955, parece ter sido determinante para a publicação do Decreto $n^{\circ} 41448$, de 18 de dezembro de $1957^{12}$. Seguindo o modelo norte-americano, a partir desse momento todos os medicamentos, nacionais e estrangeiros, passaram a ter de fazer provas de qualidade, eficácia e em parte de segurança, antes de serem introduzidos no mercado, sendo mesmo um diploma pioneiro a nível europeu ${ }^{13}$.

Em França, em 1957, cerca de cem pessoas morreram e outras tantas ficaram com deficiências motoras graves após administração de Stalinon®, um medicamento utilizado no tratamento da furunculite e que tinha sido alvo de um erro de formulação. Como consequência direta deste acidente, as autoridades de saúde francesas publicaram nova regulamentação de medicamentos em 1959. Os produtores de medicamentos passaram a ter de fazer provas prévias de qualidade, segurança e eficácia.

Ainda assim, o maior impulsionador de leis do medicamento no século XX foi, sem dúvida, o desastre da Talidomida. A Talidomida era um medicamento sedativo que mostrou ter propriedades antieméticas nos primeiros meses de gravidez e poucos efeitos tóxicos nos ensaios clínicos realizados. Foi introduzida no mercado alemão em 1956 pela firma Chemie Grunenthal® e até ao final dos anos 50 do século XX estava comercializada em mais de quarenta países por cerca de catorze empresas diferentes. A sua introdução no mercado foi um sucesso e foram precisos vários anos para que se associasse o medicamento às graves deficiências com que milhares de crianças, cujas mães tinham tomado o medicamento, nasceram. Este acontecimento representa um ponto de viragem na história da regulação do medicamento, assumindo uma importância fulcral e internacionalmente reconhecida. Há claramente, na história da regulação do medicamento, um pré e um pós Talidomida.

Se numa primeira fase os países responderam ao desastre da Talidomida a um nível nacional, até porque ainda não estava devidamente estabelecida a integração

\footnotetext{
${ }^{12}$ Ministério do Interior e da Economia - Decreto $\mathrm{n}^{\circ}$ 41448, de 18 de Dezembro de 1957 regula a introdução no mercado de novas especialidades farmacêuticas - Institui a Comissão Técnica dos Novos Medicamentos. Diário do Governo, I Série, $\mathrm{N}^{\circ}$ 287. p. 1327-1330.

${ }^{13}$ SOUSA, Micaela Figueira de; PITA, João Rui; PEREIRA, Ana Leonor - Farmácia e medicamentos em Portugal em meados do século XX: o papel da Comissão Reguladora dos Produtos Químicos e Farmacêuticos (1940). CEM/Cultura, Espaço \& Memória. Dossier temático "População e Saúde": 5 (2014), p.11-26.
} 
europeia, em 1965 a então Comunidade Económica Europeia (CEE) responde a esta tragédia com a publicação da primeira diretiva sobre especialidades farmacêuticas (Diretiva 65/65/CEE do Conselho, de 26 de janeiro relativa à aproximação das disposições legislativas, regulamentares e administrativas, respeitantes às especialidades farmacêuticas ${ }^{14}$ ), dando início ao quadro legislativo europeu em matéria de medicamentos, conhecido como Europa do Medicamento, que determinou naturalmente, a evolução do estatuto jurídico do medicamento em cada um dos Estadosmembros.

O principal objetivo desta diretiva era a execução do Mercado Único europeu em matéria de medicamentos, sem esquecer que toda a regulamentação do fabrico e distribuição de medicamentos devia ter como prioridade a proteção da Saúde Pública ${ }^{15}$ e não prejudicar o desenvolvimento da Indústria Farmacêutica europeia, tal como resulta do preâmbulo da diretiva. Para alcançar estes objetivos optou-se, numa primeira instância, por eliminar as disparidades existentes ao nível das legislações nacionais, via harmonização legislativa, e mais tarde pela implementação de procedimentos de autorização "pseudo-europeus", que pressupunham o reconhecimento mútuo dos procedimentos e ensaios levados a cabo pelos requerentes de AIM. Pretendia-se deste modo, reduzir a duplicação de esforços e evitar avaliações repetidas por mais do que um Estado membro, o que foi muito contestado e recusado, na prática, pelas autoridades reguladoras nacionais.

A Diretiva 65/65/CEE estabelecia como principal elemento regulador as AIM nacionais ${ }^{17}$. De acordo com o art. $^{\circ} 3^{\circ}$ desta diretiva, nenhuma especialidade farmacêutica podia ser comercializada num Estado membro sem ter obtido uma autorização prévia de comercialização, concedida pela respetiva autoridade competente. Para além de definir normas quanto aos procedimentos de autorização e requisitos obrigatórios a cumprir pelo requerente de AIM, definia ainda três conceitos

\footnotetext{
${ }^{14}$ Conselho - Diretiva 65/65/CEE do Conselho, de 26 de janeiro de 1965 relativa à aproximação das disposições legislativas, regulamentares e administrativas, respeitantes às especialidades farmacêuticas. $\mathrm{JO} \mathrm{n}^{\mathrm{o}} 369$ de 09 de fevereiro de 1965. p. 18-22.

${ }^{15}$ No entanto, a posição da comunidade em relação à Saúde Pública era, nesta fase, uma posição defensiva e não tanto uma posição atuante.

${ }^{16}$ FEICK, Jürgen - "Marketing authorization for pharmaceuticals in the European Union. How regulators in energy, financial services, pharmaceuticals and telecoms are coming together in european networks and agencies. ", op. cit., p. 44.

${ }^{17}$ Para Valverde este foi o "elemento realmente negativo" desta Diretiva. Segundo este autor, a Diretiva 65/65/CEE só não foi uma grande Diretiva por não ter sido capaz de atravessar fronteiras e ter-se voltado essencialmente para os "patios interiores". Cf. VALVERDE, José Luís - "El estatuto jurídico del medicamento en la unión europea", op. cit., p.12.
} 
fundamentais para a criação e implementação de um sistema regulador do medicamento: medicamento, especialidade farmacêutica e substância.

Com a sucessiva ampliação da comunidade europeia, com o desenvolvimento técnico-científico e a revolução terapêutica operada nas primeiras décadas da segunda metade do século XX, rapidamente se percebeu que o modelo existente, alicerçado na Diretiva 65/65/CEE e nas autorizações de comercialização nacionais, não trazia vantagens económicas, nem estava a ser capaz de dar resposta ao objetivo de criação do Mercado Único de medicamentos.

Assim, em 1975 foram publicadas duas importantes diretivas, que se interligam e que pretendiam, por um lado aprofundar a harmonização técnico-científica iniciada pela diretiva de 1965 e por outro lado assegurar a aplicação dos princípios por ela definidos. São elas a Diretiva 75/318/CEE ${ }^{18}$ do Conselho e a Diretiva 75/319/CEE ${ }^{19}$ do Conselho, ambas de 20 de maio de $1975^{20}$.

A primeira era uma diretiva de carácter essencialmente técnico e de elevada importância no processo de harmonização comunitária. Para além de clarificar algumas questões estatuídas pela Diretiva 65/65/CEE, nomeadamente no que diz respeito à constituição dos pedidos de AIM, veio definir as normas e os protocolos de ensaios a medicamentos (analíticos, farmacotoxicológicos e clínicos) que deveriam constar do dossier de registo da especialidade farmacêutica. Ao harmonizar estas questões, pretendia-se que os Estados membros adotassem critérios de avaliação idênticos. Deste modo evitavam-se divergências na apreciação da mesma especialidade farmacêutica, o que facilitava o comércio intracomunitário, independentemente da nacionalidade dos peritos e do Estado membro onde eram realizados os ensaios.

A Diretiva 75/319/CEE centrou-se especialmente na responsabilidade dos Estados membros em matéria de instrução dos processos, na responsabilidade dos titulares da autorização e na exigência da "pessoa qualificada", peritos com

\footnotetext{
${ }^{18}$ Conselho - Diretiva 75/318/CEE do Conselho de 20 de maio de 1975 relativa à aproximação das legislações dos Estados-membros respeitantes às normas e protocolos analíticos, tóxico-farmacológicos e clínicos em matéria de ensaios de especialidades farmacêuticas. JO no L147 de 09 de junho de 1975. p. 80-91.

${ }^{19}$ Conselho - Diretiva 75/319/CEE do Conselho, de 20 de maio de 1975 relativa á aproximação das disposições legislativas, regulamentares e administrativas respeitantes às especialidades farmacêuticas. JO $\mathrm{n}^{\circ}$ L147 de 09 de junho de 1975 p. 92-101.

${ }^{20} \mathrm{Na}$ mesma data foi publicada a Decisão 75/320 do Conselho que criou, junto da Comissão Europeia, um Comité Farmacêutico que funcionava como um órgão consultivo de apoio à Comissão em qualquer questão relacionada com o setor. Cf. Conselho da Europa - Decisão 75/320/CEE do Conselho, de 20 de maio de 1975 que institui um Comité Farmacêutico.
} 
competências nas diferentes áreas científicas do medicamento e que seriam responsáveis pelas respetivas partes do dossier de submissão. Esta diretiva veio ainda completar as disposições estabelecidas pela Diretiva 65/65/CEE e, por forma a facilitar a concessão de autorizações de comercialização em vários Estados membros, para a mesma especialidade farmacêutica, criou o Comité de Especialidades Farmacêuticas (CPMP) ${ }^{21}$, que começou a funcionar em 1977. Este comité era constituído por representantes dos Estados membros e da Comissão Europeia e era da sua competência emitir pareceres relativos à conformidade da especialidade farmacêutica com as instruções da Diretiva 65/65/CEE, ao abrigo do Procedimento CPMP que mais tarde, em 1983, veio dar lugar ao Procedimento Multiestados (Diretiva 83/570/CEE do Conselho, de 26 de outubro ${ }^{22}$ ). O CPMP desempenhava ainda uma importante função de aconselhamento científico, quer aos Estados membros, quer aos requerentes.

Ainda assim, refira-se que o Procedimento CPMP, baseado nos pareceres do CPMP funcionava como uma orientação aos Estados membros. Apesar de representar a primeira tentativa europeia de criar um mecanismo de avaliação supranacional, a verdade é que os pareceres do CPMP eram pareceres consultivos. Ou seja, o poder de decisão estava nas mãos dos Estados membros que decidiam autónoma e independentemente.

Assim, mais uma vez, a estratégia implementada fracassou. Os Estados membros continuavam a mostrar relutância em perder autonomia na avaliação de medicamentos e não havia um reconhecimento mútuo das autorizações:

"Esto há sido una constante en la historia del Derecho farmacéutico europeo. La estrategia de la armonización y el mutuo reconocimiento fracasó: “the member state's agencies did not recognise each other's authorisations or the scientific opinions of the expert committee, but preferred to evaluate the respective products on their own","23

\footnotetext{
${ }^{21}$ O primeiro Presidente do CPMP foi Léon Robert, representante do Luxemburgo. Cf. Commission of the European Communities - COM (79) 59 Final. First Commission report to the Council on the functioning of the Committee for Proprietary Medicinal Products and its impact on the development of intra-Community trade. Neste documento podemos também encontrar, no Anexo I, o regulamento interno do CPMP.

${ }^{22}$ Conselho - Diretiva 83/570/CEE do Conselho, de 26 de outubro de 1983 de modificação das Diretivas 65/65/CEE, 75/318/CEE e 75/319/CEE relativas à aproximação das disposições legislativas, regulamentares e administrativas sobre especialidades farmacêuticas. JO $\mathrm{n}^{\circ} \mathrm{L} 332$, de 28 de novembro de 1983. p. 205-214.

${ }^{23}$ Krapohl, S. - Risk regulation in the Single Market. The Governance of Pharmaceuticals and Foodstuffs in the European Union Cit. por SÁENZ, Francisco Miguel Bombillar- Intervención administrativa y régimen jurídico del medicamento en la unión europea. Granada: Universidad de Granada, 2010. Tese de Doutoramento.p.116
} 
Do outro lado, a própria Indústria Farmacêutica não se mostrava interessada em recorrer a este procedimento, pois não o considerava útil para atingir os seus objetivos que passavam, nomeadamente, pela implementação de um mercado de medicamentos de dimensão comunitária. Na opinião da indústria a resolução do problema passava pela instituição de um procedimento assente num "verdadeiro sistema de reconhecimento mútuo das autorizações nacionais pelos Estados membros" $" 24$.

É neste contexto que se chega ao final dos anos 80 que têm como pano de fundo a decisão do Conselho Europeu de pôr em prática e efetivar o Mercado Único europeu e cujo plano de ação foi corporizado no Ato Único Europeu ${ }^{25}$ (AUE -1987) e no Livro Branco, que definiam um conjunto de medidas que era necessário tomar para que se conseguisse alcançar o Mercado Único em 1992. É também nesta década que vários países aderem à CEE, nomeadamente Portugal e Espanha. $\mathrm{O}$ alargamento da comunidade levantava novos desafios, o que se repercutiu necessariamente na política do medicamento a nível europeu.

Todas estas questões, associadas à relativa inoperância do Procedimento Multiestados, começavam por esta altura a reforçar a necessidade de proceder a uma profunda reforma do modelo europeu de avaliação de medicamentos.

A primeira medida tomada como resposta à necessidade de concluir a realização do mercado interno, também no que respeita às especialidades farmacêuticas, foi feita pela mão da Diretiva 87/22/CEE do Conselho, de 22 de dezembro de $1987^{26}$ que deu um passo em frente em direção aos procedimentos comunitários de avaliação de medicamentos ${ }^{27}$. De acordo com esta diretiva, as autoridades nacionais tinham

\footnotetext{
${ }^{24}$ Já para as associações europeias representativas dos interesses dos consumidores, a solução passava por um sistema de autorizações comunitárias da responsabilidade de um "bureau" europeu. Cf. CAVACO, António C. C. - A Construção da Europa do Medicamento. Um desafio do Mercado Único. Porto: Ordem dos Farmacêuticos, 1992. p. 132.

${ }^{25}$ Comissão Europeia - Acto Único Europeu. JO n ${ }^{\circ}$ L169, de 29 de junho de 1987.

${ }^{26}$ Conselho - Diretiva 87/22/CEE do Conselho, de 22 de Dezembro de 1986 relativa à aproximação das medidas nacionais respeitantes à colocação no mercado dos medicamentos de alta tecnologia, nomeadamente dos resultantes da biotecnologia. JO nº15, de 17 de janeiro de 1987. p. 38-41.

${ }^{27}$ É ainda de referir a publicação da Conselho - Diretiva 87/19/CEE do Conselho, de 22 de Dezembro de 1986 que modifica a Diretiva 75/318/CEE relativa à aproximação das legislações dos Estados-membros sobre normas e protocolos analíticos, tóxico-farmacológicos e clínicos em matéria de ensaios de especialidades farmacêuticas. JO n $\mathrm{n}^{\mathrm{O}} \mathrm{L} 15$ de 17 de janeiro de 1987. p. 31-33. Esta diretiva criou um Comité para a Adaptação ao Progresso Técnico das Diretivas Relacionadas com a Supressão dos Obstáculos Técnicos às Trocas Intracomunitárias no Setor das Especialidades Farmacêuticas, que funcionava como um elo de ligação entre a Comissão e os Estados membros com o objetivo de estabelecer um procedimento rápido de adaptação ao progresso técnico das exigências em matéria de
} 
obrigatoriamente de recorrer ao CPMP nos casos em que estivesse em causa a avaliação de medicamentos de alta tecnologia, em especial os biotecnológicos ${ }^{28}$. Neste contexto foi criado um mecanismo comunitário de concertação - Procedimento de Concertação que precedia as decisões nacionais na apreciação dos dossiers de AIM de medicamentos de alta tecnologia, em especial os biotecnológicos e que mais tarde, ainda no final dos anos 80 do século $\mathrm{XX}$, foi alargado aos medicamentos imunológicos, derivados do plasma e sangue humanos e aos radiofármacos. Isto porque, no entender da Comissão Europeia, só é possível favorecer a investigação, produção e distribuição destes medicamentos numa ótica de mercado alargado.

O Procedimento Multiestados e o Procedimento de Concertação, apesar de não poderem ser considerados verdadeiramente europeus, pelo facto de o poder de decisão não estar centralizado a nível europeu, foram muito importantes do ponto de vista técnico-científico. Sendo o CPMP constituído por representantes dos Estados membros, que reuniam periodicamente em Bruxelas para discutir as questões técnico-científicas resultantes da avaliação de medicamentos, foi criando um ambiente favorável para que os critérios de avaliação nacionais se aproximassem cada vez mais dos critérios de avaliação comunitários, com claro benefício para as autoridades reguladoras nacionais individualmente, mas também para o sistema comunitário como um todo ${ }^{29}$.

Assim, no final da $1^{\text {a }}$ fase da Europa do Medicamento estávamos perante a existência de dois procedimentos de avaliação de medicamentos ditos comunitários: o Procedimento Multiestados, válido quando o requerente solicitava o reconhecimento de uma AIM, concedida por um Estado membro, a pelo menos outros dois Estados membros e o Procedimento de Concertação, obrigatório para os medicamentos de alta tecnologia.

\section{A $2^{a}$ fase da Europa do Medicamento (1995-2004) e o "Novo Sistema"}

\section{Europeu de Avaliação e Supervisão do Medicamento}

ensaios de medicamentos estipuladas pela Diretiva 75/318/CEE, modificada pela Diretiva 83/570/CEE. Para além disso estabeleceu as primeiras normas relativas às Boas Práticas de Laboratório.

${ }^{28}$ Esta medida, mesmo que indiretamente, pois não foi esse o seu grande objetivo, acaba por estabelecer uma distinção entre medicamentos inovadores e não inovadores.

${ }^{29}$ SILVA, J.A. Aranda da - A Europa do Medicamento Ano 2000 O Futuro Já Começou. op. cit. 
Apesar dos passos dados na $1^{\text {a }}$ fase em direção à harmonização técnica e científica, a verdade é que a livre circulação de medicamentos entre os Estados membros não era uma realidade.

Esta $2^{\mathrm{a}}$ fase caracterizou-se por várias alterações políticas ao nível da Comunidade. O AUE publicado em 1986 e que entrou em funcionamento em 1987, consubstanciou uma profunda revisão dos Tratados Europeus com o grande objetivo de efetivação do Mercado Único de mercadorias. Por outro lado, os Tratados de Maastricht (1992) e de Amesterdão (1997) representam o abandono da política europeia do domínio exclusivamente económico, para se lançar também no domínio da cidadania. Como consequência das políticas traçadas, há uma maior preocupação para com os consumidores e para com as políticas sociais, o que se vai necessariamente refletir na política europeia do medicamento.

Durante a Presidência Portuguesa do Conselho Europeu de 1992, foram aprovadas uma série de diretivas designadas de "uso racional do medicamento" e que estabeleceram normas comunitárias quanto à rotulagem, folheto informativo, publicidade e distribuição de medicamentos e que espelham, pela primeira vez, a preocupação da comunidade para com a informação que chega aos consumidores.

A Presidência Portuguesa do Conselho Europeu de 1992 representa um marco decisivo na história da Europa do Medicamento. Para além das diretivas relacionadas com o "uso racional do medicamento", é durante a Presidência Portuguesa que se alcança finalmente o consenso quanto à estrutura do "Novo Sistema" Europeu de Avaliação e Autorização de Medicamentos.

Perante a inoperância dos Procedimentos de Concertação e Multi-Estados, estabelecidos durante a $1^{\mathrm{a}}$ fase, e atendendo à necessidade de defender a posição da Indústria Farmacêutica dentro de uma perspetiva de desenvolvimento terapêutico e económico, estava claro que era necessário proceder a uma revisão dos procedimentos de AIM comunitários. Esta revisão teria de passar necessariamente pela implementação definitiva da avaliação comunitária em detrimento da avaliação nacional.

Assim, em 1988 a Comissão Europeia iniciou um extenso processo de consulta aos vários interessados do setor, nomeadamente aos Estados membros, às associações representantes da Indústria Farmacêutica, aos organismos representativos dos consumidores e às associações profissionais, que culmina com a publicação da comunicação da Comissão intitulada Futuro sistema para a livre circulação de 
medicamentos na Comunidade Europeia ${ }^{30}$. As propostas apresentadas pela Comissão passavam pela criação de uma agência europeia de avaliação de medicamentos, pela criação de um procedimento de avaliação centralizado e pelo reforço das competências comunitárias no que respeita ao reconhecimento das autorizações entre os Estados membros. No entanto, a agência proposta, baseava-se num modelo centralizado ao estilo Federal Food and Drug Administration (FDA), o que levou desde logo à discordância de vários Estados membros que não queriam perder autonomia e poder na avaliação de medicamentos. Após várias reuniões, discussões, emendas ${ }^{31}$ e sugestões, foi durante a Presidência Portuguesa, numa reunião no Centro Cultural de Belém, que se chegou a acordo sobre o modelo de funcionamento da agência a criar. Ficou decidido que a sua estrutura se iria basear num modelo descentralizado assente em três grandes pilares: as agências reguladoras nacionais, a Comissão Europeia e a própria Agência Europeia de Avaliação de medicamentos (EMEA).

Estavam assim lançadas as bases do Sistema Europeu de Avaliação e Autorização de Medicamentos, que, no que respeita aos medicamentos de uso humano, foi corporizado nos seguintes atos legislativos:

- Diretiva 93/39/CEE, de 14 de junho de 1993 que altera as Diretivas 65/65/CEE, 75/318/CEE e 75/319/CEE ${ }^{32}$;

- Diretiva 93/41/CEE, de 14 de junho de 1993 que revoga a Diretiva 87/22/CEE, relativa à aproximação das medidas nacionais respeitantes à colocação no mercado dos medicamentos de alta tecnologia, nomeadamente dos resultantes da biotecnologia ${ }^{33}$;

\footnotetext{
${ }^{30}$ Comissão Europeia - COM (90) 283 final. JO n ${ }^{\circ}$ C330, de 31 de Dezembro de 1990.

${ }^{31}$ Uma das emendas feitas foi a alteração da base jurídica da proposta. A $1^{\text {a }}$ proposta de Regulamento da Comissão (1990) baseava-se no art. ${ }^{\circ} 100^{\circ}$ do AUE. José-Luis Valverde, como relator do Parlamento Europeu, propôs a sua alteração para o art. $^{\circ} 235^{\circ}$, que assinalava que o Conselho Europeu podia, por unanimidade, aprovar uma norma desde que a considerasse necessária e coerente com os objetivos do Tratado. A segunda emenda apresentada foi a alteração do instrumento jurídico. Em vez de Diretiva propôs-se que a proposta fosse apresentada sob a forma de Regulamento, que na opinião do proponente, José-Luís Valverde, é o instrumento jurídico 100\% comunitário. Para um estudo mais aprofundado sobre o processo legislativo acerca desta matéria veja-se VALVERDE, José Luis - "El estatuto jurídico del medicamento en la unión europea" op. cit.

${ }^{32}$ Conselho - Diretiva 93/39/CEE do Conselho de 14 de junho de 1993 que altera as Diretivas 65/65/CEE, 75/318/CEE e 75/319/CEE respeitantes às especialidades farmacêuticas. JO nº L214 de 24 de agosto de 1993. p. 22-30.

${ }^{33}$ Conselho - Diretiva 93/41/CEE do Conselho de 14 de junho de 1993 que revoga a Diretiva 87/22/CEE, relativa à aproximação das medidas nacionais respeitantes à colocação no mercado dos medicamentos de
} 
- Regulamento (CEE) N $2309 / 93$ do Conselho de 22 de julho de 1993 que estabelece procedimentos comunitários de autorização e fiscalização de medicamentos de uso humano e veterinário e institui uma Agência Europeia de Avaliação de Medicamentos ${ }^{34}$.

Com a criação da EMEA nasceu um sistema de avaliação de medicamentos verdadeiramente europeu caracterizado por três procedimentos de avaliação de medicamentos: o Procedimento Centralizado, o Procedimento de Reconhecimento Mútuo e o Procedimento Nacional.

O recém-criado Procedimento Centralizado, com as necessárias adaptações, veio substituir o Procedimento de Concertação e baseava-se na avaliação da EMEA via $\mathrm{CPMP}^{35}$. Nesta altura era obrigatório para os medicamentos de alta-tecnologia, em especial os biotecnológicos e opcional para os inovadores, pelo que se tratou essencialmente duma reforma de procedimentos ${ }^{36}$.

O Procedimento de Reconhecimento Mútuo, antigo Multiestados, baseava-se nas autorizações nacionais e no reconhecimento das avaliações e autorizações pelos restantes Estados membros.

O Procedimento Nacional era válido no Estado membro avaliador e funcionava como base do Procedimento de Reconhecimento Mútuo.

Apesar de ter inovado no que respeita aos procedimentos de avaliação disponíveis e em determinadas questões administrativas, este "novo" sistema continuava a basear-se nos requisitos técnico-científicos estabelecidas nos anos 60 e 70 do século XX, em particular pelas Diretivas 65/65/CEE, 75/318/CEE, 75/319/CEE e suas alterações. Isto numa altura em que o TUE (1992) estabelecia uma nova visão da

alta tecnologia, nomeadamente dos resultantes da biotecnologia. JO nº L214, de 24 de agosto de 1993. p. 40 .

${ }^{34}$ Conselho - Regulamento (CEE) No 2309/93 do Conselho de 22 de julho de 1993 que estabelece procedimentos comunitários de autorização e fiscalização de medicamentos de uso humano e veterinário e institui uma Agência Europeia de Avaliação de Medicamentos.

35 O Regulamento 2309/93 veio dar novas competências e responsabilidades científicas ao CPMP. O CPMP criado pela Diretiva 75/319/CEE era um órgão técnico-científico sem grandes poderes na avaliação de medicamentos e funcionava sobretudo como um organismo de arbitragem. As competências e responsabilidades do CPMP foram evoluindo paralelamente à evolução da Europa do Medicamento. Com o novo sistema, o CPMP passa a ser um dos comités científicos da EMEA, juntamente com o Comité de Medicamentos Veterinários (CVMP), e passa a ter um papel decisivo na avaliação de medicamentos através do procedimento centralizado, para além do tradicional papel de arbitragem em situações de divergência de opiniões entre os Estados membros no decorrer do Procedimento de Reconhecimento Mútuo.

36 SÁENZ, Francisco Miguel Bombillar - Intervención administrativa y régimen jurídico del medicamento en la unión europea. op. cit. 
Europa enquanto união, a qual foi continuada e desenvolvida no Tratado de Amesterdão, assinado em 1997. A política europeia deixava a dimensão exclusivamente económica para se lançar também em questões sociais como a defesa da Saúde Pública, a defesa dos consumidores e a proteção do meio ambiente. Todas estas questões tinham necessariamente de se refletir na política do medicamento europeia e deviam ser tidas em consideração na revisão do sistema, desde logo prevista pelo art. $71^{\circ}$ do Regulamento (CE) $n^{\circ} 2309 / 93$.

Ainda nesta fase, mais precisamente em 2001 foi publicada a Diretiva 2001/83/CE do Parlamento Europeu e do Conselho, de 6 de novembro de $2001^{37}$, conhecida por Código Comunitário relativo aos Medicamentos de Uso Humano. Pela sua natureza jurídica, esta diretiva não procedeu a alterações às diretivas existentes em matéria de medicamentos de uso humano. Dada a dispersão existente na matéria, o seu propósito foi reunir num único texto legal as várias diretivas publicadas anteriormente. O objetivo era simplificar o sistema e torná-lo mais " $u$ ser friendly",38.

Por último e pela sua importância para a harmonização global levada a cabo desde o início dos anos 90 via International Conference on Harmonization $\left(\mathrm{ICH}^{39}\right)$ refira-se a publicação da Diretiva 2003/63/CE da Comissão de 25 de junho de $2003^{40}$. Esta diretiva incorporou no Sistema Europeu de Avaliação e Autorização de Medicamentos o Common Technical Document (CTD). O modelo de submissão de pedidos de AIM, reconhecido como formato em partes (Partes I - IV) estabelecido pela Diretiva 65/65/CEE e suas alterações, era assim substituído pelo formato CTD, maioritariamente igual em todas as regiões ICH (EUA, Japão e UE). O objetivo da implementação de um modelo de submissão de AIM harmonizado internacionalmente era diminuir o tempo e os recursos necessários à elaboração de um dossier de AIM, facilitar as submissões eletrónicas (eCTD) e a troca de informação entre as autoridades reguladoras. Não se pretendia alterar os requisitos técnico-científicos, mas antes

\footnotetext{
${ }^{37}$ Parlamento Europeu e Conselho - Diretiva 2001/83/CE do Parlamento Europeu e do Conselho, de 6 de novembro de 2001 que estabelece um código comunitário relativo aos medicamentos para uso humano. JO n ${ }^{\circ}$ L311 de 28 de novembro de 2001. p. 67-128.

38 DEBOYSER, Patrick - Política Europeia do Medicamento. 1as Jornadas do INFARMED. As políticas nacionais face à internacionalização. Lisboa: INFARMED, 1997.

${ }^{39}$ Em 23 de outubro de 2015 passou a designar-se International Council for Harmonization (ICH).

${ }^{40}$ Comissão Europeia - Diretiva 2003/63/CE da Comissão de 25 de junho de 2003, que altera a Diretiva 2001/83/CE do Parlamento Europeu e do Conselho que estabelece um código comunitário relativo aos medicamentos para uso humano. JO n L159 de 27 de junho de 2003. p. 46-94.
} 
fornecer um modelo de submissão que fosse válido em todas as regiões $\mathrm{ICH}^{41}$. Não se tratou de uma alteração técnico-científica mas antes de uma alteração administrativa com vista à harmonização global.

\section{A $3^{\text {a }}$ fase da Europa do Medicamento (2001 - 2015). A reforma legislativa} do sistema e a necessidade de responder aos novos desafios em matéria de política europeia e de Saúde Pública

De acordo com o art. $71^{\circ}$ do Regulamento (CE) no 2309/93: “...no prazo de seis anos após a entrada em vigor do presente regulamento, a Comissão publicará um relatório geral sobre a experiência adquirida com a aplicação dos procedimentos previstos no presente regulamento, no capítulo III da Diretiva 75/319/CEE e no capítulo IV da Diretiva 81/851/CEE.".

Para além de prevista pela legislação comunitária, esta revisão impunha-se não só como uma necessidade para responder aos novos desafios europeus ${ }^{42}$ e à perda de competitividade da Indústria Farmacêutica europeia, mas também porque em 2004, dez novos Estados membros iriam integrar a União Europeia. A estrutura do Sistema Europeu de Avaliação e Autorização de Medicamentos, altamente dependente e relacionada com as agências reguladoras nacionais, tinha de se adaptar a este alargamento, sob pena de não cumprir com os objetivos traçados.

A elaboração deste relatório foi atribuída ao Consórcio CMS Cameron McKenna \& Andersen Consulting ${ }^{43}$. Trata-se de um extenso relatório que faz importantes

\footnotetext{
${ }^{41}$ Sobre o processo de discussão ICH e evolução do formato CTD veja-se HARRON, Dean W.G. "Technical requirements for registration of pharmaceuticals for human use: the ICH process" In Griffin, John P. The Textbook of Pharmaceutical Medicine. . 6th Edition. Oxford: BMJ Books, 2009. p. 522533.; International Conference on Harmonisation of Technical Requirements for Registration of Pharmaceuticals for Human Use - The value and benefits of ICH to Drug Regulatory Authorities advancing harmonization for better health. Geneva: ICH, 2010.

${ }^{42}$ A resposta a estes desafios tem sido dada no contexto das alterações à política comunitária em matéria de Saúde Pública, decorrentes do Tratado de Maastricht, com a evolução do Tratado de Amesterdão e mais recentemente do Tratado de Lisboa, mas também teve em conta o objetivo estratégico da União, definido no Conselho Europeu de Lisboa 2002: “... construir a economia baseada no conhecimento mais dinâmica e competitiva do mundo, capaz de garantir um crescimento económico sustentável, com mais e melhores empregos, e com maior coesão social.".

${ }^{43}$ Comissão Europeia - Directorate-General Enterprise Pharmaceuticals and Cosmetics - Evaluation of the operation of Community procedures for the authorisation of medicinal products. . Evaluation carried out on behalf of the European Commission by CMS Cameron McKenna and Andersen Consulting. London: 2001. Ver também Comissão Europeia - COM (2001) 606 Final. Report from the Commission on the experience acquired as a result of the operation of the procedures for granting marketing authorisations for medicinal products laid down in Regulation (EEC) $\mathrm{N}^{\circ} 2309 / 93$, in chapter
} 
considerações e avaliações acerca do sistema regulamentar do medicamento a nível europeu, desde os procedimentos de avaliação de medicamentos até aos sistemas de Farmacovigilância, passando pelas questões relacionadas com a informação e publicidade, classificação de medicamentos, fabrico, distribuição por grosso, acesso ao mercado, transparência dos procedimentos, entre outras. As recomendações feitas por este relatório para a reforma da legislação farmacêutica europeia ficaram conhecidas por Review 2001.

De um modo geral, todas as partes interessadas se mostraram satisfeitas com o sistema implementado nos anos 90. Apesar de algumas críticas em relação a determinadas especificidades, a opinião geral era positiva. Ambos os procedimentos comunitários eram vistos como complementares e como beneficiadores dos objetivos da União. Todas as partes consultadas defendiam que deviam continuar a funcionar de forma paralela. Se o Procedimento Centralizado aparecia como potenciador e facilitador da inovação farmacêutica, o Procedimento de Reconhecimento Mútuo, pela sua flexibilidade acabava por responder melhor às necessidades das pequenas e médias empresas farmacêuticas.

Depois de extensas reuniões e discussões entre as partes interessadas (autoridades reguladoras nacionais, via Heads of Medicines Agency - HMA, EMEA e European Federation of Pharmaceutical Industries and Associations - EFPIA) a Comissão Europeia apresentou, a 26 de novembro de $2001^{44}$, uma proposta de reforma da legislação farmacêutica europeia que pretendia responder a três principais objetivos: assegurar a contínua proteção da Saúde Pública, fomentar o Mercado Único e a competitividade da Indústria Farmacêutica europeia e preparar o alargamento da União. Após mais de dois anos de reuniões, discussões e emendas entre Comissão, Parlamento e Conselho Europeus, características do procedimento legislativo europeu, atingiu-se finalmente o consenso a 31 de março de 2004 e foram publicados os quatro instrumentos legislativos que corporizam a reforma ambicionada:

- Regulamento (CE) no 726/2004 do Parlamento Europeu e do Conselho de 31 de março de 2004 que estabelece os procedimentos comunitários de autorização e supervisão de

III of directive 75/319/EEC and chapter IV of directive 81/851/EEC. Report on the basis of Article 71 of Regulation (EEC) No 2309/93.

${ }^{44}$ Comissão Europeia - COM (2001) 404 final. 
medicamentos de uso humano e veterinário e institui a Agência Europeia de Medicamentos ${ }^{45}$;

- Diretiva 2004/27/CE do Parlamento Europeu e do Conselho de 31 de março de 2004 que altera a Diretiva 2001/27/CE que estabelece um Código Comunitário relativo aos Medicamentos para Uso Humano ${ }^{46}$;

- Diretiva 2004/28/CE do Parlamento Europeu e do Conselho de 31 de março de 2004 que altera a Diretiva 2001/82/CE que estabelece um Código Comunitário relativo aos Medicamentos para Uso Veterinário ${ }^{47}$;

- Diretiva 2004/24/CE do Parlamento Europeu e do Conselho de 31 de março de 2004 que altera, em relação aos medicamentos tradicionais à base de plantas, a Diretiva 2001/83/CE que estabelece um Código Comunitário relativo aos Medicamentos para Uso Humano $^{48}$.

As alterações introduzidas distribuíram-se por três grandes áreas ${ }^{49}$ : estrutura da Agência Europeia do Medicamento (EMA); procedimentos de avaliação e sistemas de Farmacovigilância; transparência e informação. Mais concretamente, a Diretiva 2004/27/CE procurou criar os mecanismos necessários para responder às políticas europeias em matéria de Saúde Pública, nomeadamente através de uma maior vigilância dos medicamentos, simplificar o sistema e torna-lo mais eficiente e transparente, assegurar que o sistema europeu de avaliação e vigilância do medicamento era capaz de

\footnotetext{
${ }^{45}$ Parlamento Europeu e Conselho - Regulamento (CE) $\mathrm{n}^{\mathrm{o}} 726 / 2004$ do Parlamento Europeu e do Conselho, de 31 de março de 2004 que estabelece procedimentos comunitários de autorização e de fiscalização de medicamentos para uso humano e veterinário e que institui uma Agência Europeia de Medicamentos. JO $\mathrm{n}^{\mathrm{O}} \mathrm{L} 136$, de 30 de abril de 2004. p. 1-51.

${ }^{46}$ Parlamento Europeu e Conselho - Diretiva 2004/27/CE do Parlamento Europeu e do Conselho de 31 de março de 2004 que altera a Diretiva 2001/83/CE que estabelece um código comunitário relativo aos medicamentos para uso humano. JO n ${ }^{\circ} 136$ de 30 de abril de 2004. p. 34-57.

${ }^{47}$ Parlamento Europeu e Conselho - Diretiva 2004/28/CE do Parlamento Europeu e do Conselho de 31 de março de 2004 que altera a Diretiva 2001/82/CE que estabelece um Código Comunitário relativo aos Medicamentos para Uso Veterinário. JO L136 de 30.04.2004. p. 58-84.

${ }^{48}$ Parlamento Europeu e Conselho - Diretiva 2004/24/CE do Parlamento Europeu e do Conselho de 31 de março de 2004 que altera, em relação aos medicamentos tradicionais à base de plantas, a Diretiva 2001/83/CE que estabelece um código comunitário relativo aos medicamentos para uso humano. JO nº 136 de 30 de abril de 2004. p. 85-90.

${ }_{49}$ IVO, Rui Santos - Revisão do sistema europeu de medicamentos. Reforçar os Mecanismos de Protecção da Saúde Pública. Boletim do CIM - Centro de informação do medicamento. Ordem dos Farmacêuticos. In Revista da Ordem dos Farmacêuticos, Ano XI, nº 61: (2004), p.1-2.
} 
responder ao alargamento da União, ao mesmo tempo que se focou na necessidade de favorecer a competitividade e inovação da Indústria Farmacêutica ${ }^{50}$.

Interessam para esta análise essencialmente o Regulamento (CE) no 726/2004 e a Diretiva 2004/27/CE.

No que diz respeito à Agência Europeia de Avaliação de Medicamentos (EMEA), as alterações começaram desde logo por alterações simbólicas, nomeadamente alteração do nome das instituições. A EMEA passou a designar-se Agência Europeia do Medicamento (EMA) e o CPMP passou a designar-se Comité de Medicamentos de Uso Humano (CHMP). Para além deste comité científico e do correspondente para os medicamentos veterinários, CVMP, foram incluídos na estrutura da Agência, o Comité de Medicamentos Órfãos, COMP, o Comité de Medicamentos Tradicionais à Base de Plantas, HMPC e foi prevista a inclusão do Comité Pediátrico, PDCO. Mais tarde, em 2007, foi instituído o Comité das Terapias Avançadas (CAT) e, em 2012, o Comité de Avaliação do Risco e Farmacovigilância (PRAC), também eles integrados na atual estrutura administrativa da Agência.

No que respeita à estrutura propriamente dita, as alterações passaram essencialmente pela composição dos quadros administrativos e científicos das instituições, nomeadamente pela redução do número de representantes por Estado membro, por forma a poder responder ao alargamento da União.

No que respeita aos procedimentos de avaliação, o Procedimento Centralizado passou a ser obrigatório também para os medicamentos destinados ao tratamento da SIDA, cancro, doenças neuro-degenerativas, diabetes e para os medicamentos órfãos ${ }^{51}$. Paralelamente ao Procedimento de Reconhecimento Mútuo foi criado o Procedimento Descentralizado, como uma variante daquele, procurando deste modo facilitar o reconhecimento mútuo das avaliações e autorizações entre os Estados membros. Seguindo o mesmo princípio, foi criado um grupo de coordenação, o Co-ordination Group for Mutual Recognition and Decentralised Procedures - Human (CMDh), institucionalizado a partir do Mutual Recognition Facilitation Group (MRFG) existente

\footnotetext{
${ }^{50}$ Muitas destas questões resultaram da análise feita pela Comissão, mais precisamente pelo Grupo G10 e retratadas na Comunicação da Comissão de 1 de julho de 2003 (COM (2003) 383 Final). Este é um grupo de alto nível criado pela Comissão e constituído, entre outros, por Comissários de saúde e empresa, Ministros da Saúde e Indústria de vários Estados membros com o objetivo de discutir os problemas do setor farmacêutico.

${ }^{51}$ Em 2009 este procedimento passou a ser obrigatório também para os medicamentos destinados ao tratamento de doenças auto-imunes e virais.
} 
desde 1995, para facilitar a discussão e fomentar o consenso entre os Estados membros envolvidos na avaliação, procurando assim evitar o recurso a arbitragens, via CHMP.

Relativamente às AIM propriamente ditas, a reforma de 2004 introduziu o princípio da validade ilimitada após a primeira renovação, ao fim de cinco anos ${ }^{52}$, a caducidade de AIM sempre que o medicamento não seja comercializado durante três anos (sunset clause) e que a relação benefício/risco desfavorável passa a ser motivo suficiente para a recusa, suspensão ou retirada do medicamento do mercado.

Relativamente aos medicamentos genéricos foram também tomadas importantes medidas. Pela primeira vez foi estabelecida na legislação comunitária a definição de medicamento genérico e de medicamento de referência europeu e, por forma a favorecer o mercado destes medicamentos, foi harmonizado o período de exclusividade de dados em todo o espaço comunitário, passando de seis ou dez anos, para oito anos. Ao fim deste tempo os pedidos de AIM de medicamentos genéricos podem ser submetidos às respetivas autoridades reguladoras. No entanto, não podem ser comercializados antes dos dez anos, período de exclusividade de mercado, extensível até aos onze anos, desde que nos primeiros oito anos o titular de AIM obtenha uma autorização para uma, ou mais, nova indicação terapêutica com benefício clínico significativo ${ }^{53}$.

$\mathrm{Na}$ área da Farmacovigilância a reforma legislativa procurou reforçar e desenvolver a regulamentação existente, melhorando os mecanismos de comunicação não só europeus, mas também internacionais.

A política de informação e transparência, que já tinha começado a estabelecer-se nos anos 90, foi evoluindo a par com a Europa do Medicamento, prevendo-se a publicação dos vários atos, medidas e decisões, nomeadamente quanto à retirada de medicamentos do mercado, indeferimento de pedidos de AIM, Relatórios Europeus de Avaliação (EPAR's) incentivando-se o uso de linguagem simples e percetível pelo público em geral.

\section{Considerações finais}

\footnotetext{
${ }^{52}$ Na primeira renovação a relação benefício/risco é reavaliada e a renovação só é deferida nos casos em que esta relação se mantém positiva.

${ }^{53}$ Esta norma é conhecida como Cláusula Bolar $(8+2+1)$ e procura favorecer o mercado de medicamentos genéricos pois permite a sua comercialização imediatamente após a caducidade da patente, sem ter de esperar que a patente caduque para ter de submeter o dossier de AIM do medicamento genérico.
} 
A Europa do medicamento tem início nos anos 60 do Século $\mathrm{XX}$ e a sua evolução espelha em grande parte o que foi a integração europeia em outras áreas dentro da dinâmica económica e social.

Numa primeira fase, os objetivos eram essencialmente económicos. A harmonização técnico-científica operada nos anos 60 e 70 do século XX tinha como fim último alcançar o Mercado Único de medicamentos, eliminando barreiras entre os Estados membros, por forma a fomentar o desenvolvimento da Indústria Farmacêutica europeia. Numa segunda fase e refletindo a mudança de atitude das políticas europeias, as alterações empreendidas acrescentaram uma maior preocupação para com a defesa da Saúde Pública e os interesses dos consumidores, sem nunca esquecer os interesses económicos numa área tão importante para as balanças económicas dos Estados membros mas também para a União Europeia como um todo.

A consolidação da Europa do Medicamento só foi feita nos anos $90 \mathrm{com}$ a criação da EMEA, atual EMA, baseada num modelo descentralizado em articulação direta com a Comissão Europeia e com as agências reguladoras nacionais.

Nas últimas décadas a Europa do Medicamento deixou de se focar essencialmente na institucionalização do sistema, para se lançar na especialização e diferenciação, tendo como pano de fundo a garantia de qualidade, segurança e eficácia dos medicamentos, sob a égide da Agência e da sua estrutura administrativa, sem esquecer a política económica e neste contexto a defesa e promoção da Indústria Farmacêutica europeia.

Esta nova visão europeia está patente desde logo na regulamentação dos medicamentos pediátricos, feita pelos Regulamentos (CE) no 1901/2006 e 1902/2006, de 12 de dezembro de 2006, e dos medicamentos de terapia avançada, feita pela Diretiva 2009/120/CE da Comissão, de 14 de setembro de 2009 e pela consequente criação e implementação dos respetivos comités no seio da EMA (PDCO e CAT).

Mais recentemente a União lançou-se na luta contra os medicamentos contrafeitos, Diretiva 2011/62/UE do Parlamento Europeu e do Conselho de 1 de julho 2011 e no reforço dos mecanismos de Farmacovigilância no âmbito europeu e internacional, Diretiva 2012/26/UE do Parlamento Europeu e do Conselho, de 25 de outubro de 2012 e Regulamento (UE) n ${ }^{\circ}$ 1027/2012 do Parlamento Europeu e do Conselho de 25 de outubro de 2012.

Todas estas medidas acabaram por reforçar as competências da Agência como instituição reguladora, sobretudo no que diz respeito ao seu objetivo de defesa da Saúde 
Pública. A Agência tem vindo a reforçar a sua posição a nível europeu, através da cooperação com as autoridades reguladoras nacionais, que acabam por representar um importante suporte da sua atividade, mas também com outras instituições europeias, nomeadamente a European Food and Safety Agency (EFSA) e a European Centre for Disease Prevention and Control $(E C D C)$, sobretudo no que respeita à saúde humana e animal. Do ponto de vista internacional, a Agência também tem vindo a implementar-se e a reforçar os mecanismos de cooperação, com uma clara tendência para a globalização internacional no setor regulamentar da área farmacêutica e que já vem a ser estabelecido desde os anos 90. Esta globalização tem as suas vantagens, mas também acarreta riscos que têm de ser considerados e contra os quais é preciso uma atuação urgente e de nível global. Falamos nomeadamente da descentralização da investigação clínica ${ }^{54}$ e da produção de substâncias ativas fora da União Europeia, procurando países onde essas atividades possam ter custos mais reduzidos, o que levanta novos desafios e responsabilidades à Agência no seio da defesa da saúde humana e animal que ficaram corporizados nomeadamente na diretiva dos medicamentos contrafeitos.

Nos últimos anos a EMA teve de se adaptar e de adaptar a sua estrutura não só ao desenvolvimento técnico-científico em matéria de medicamentos (HIV, doenças neurodegenerativas, cancro, produtos biológicos, etc.) mas também aos novos desafios em matéria de Saúde Pública. Falamos nomeadamente da resistência medicamentosa (antibióticos), da atuação perante epidemias e pandemias (influenza virus H5N1, ébola), da necessidade de responder às novas tecnologias de saúde, entre tantos outros desafios. Em 2009 teve lugar uma nova auditoria ao sistema, desta feita entregue à Ernst \& Young et Associés ${ }^{55}$ e que pretendia avaliar a eficácia e a eficiência da Agência, avaliando consequentemente o sistema europeu de avaliação de medicamentos não só do ponto de vista europeu, mas também do ponto de vista internacional, tendo como elemento central de análise o Procedimento Centralizado. A metodologia utilizada foi semelhante à utilizada em 2004, ou seja, baseou-se em questionários e entrevistas realizados às partes interessadas, nomeadamente à EMA, às agências reguladoras

\footnotetext{
${ }^{54}$ Para se ter uma ideia, nos pedidos de AIM feitos à agência entre 2005-2009, apenas 38,8\% dos pacientes envolvidos nos ensaios clínicos receberam o seu tratamento experimental através de ensaios clínicos desenvolvidos na UE ou EEA. Cf. European Medicines Agency - Annual report 2010. London: EMA, 2011a.

${ }^{55}$ European Commission - Evaluation of the European Medicines Agency Brussels: Evaluation carried out on behalf of the European Commission by Ernst \& Young et Associés 2010.
} 
nacionais, à Indústria Farmacêutica, às associações de pacientes e consumidores, entre outras.

A auditoria revelou que a EMA poderá estar a atingir a sua capacidade máxima. Ficou patente que apesar de a EMA ter contribuído para a defesa da saúde humana e animal e ter contribuído para a harmonização do mercado interno, deve ter em atenção a efetiva comercialização dos medicamentos aprovados pelo Procedimento Centralizado, pois muitos destes produtos são disponibilizados em apenas alguns mercados europeus. A título de exemplo refira-se um estudo de 2013 que refere que em Portugal mais de $40 \%$ dos medicamentos avaliados não estão disponíveis, mesmo 5 anos após obterem uma autorização de comercialização comunitária ${ }^{56}$.

Este documento acabou por levar à publicação do EMA Road Map to $2015^{57}$ que definiu três áreas estratégicas de desenvolvimento do Sistema Europeu de Avaliação e Autorização de Medicamentos e que devem orientar as ações da agência neste período: responder às necessidades de Saúde Pública, melhorar o acesso a medicamentos e otimizar a utilização segura dos medicamentos. Assim, a Agência deve procurar facilitar e estimular o desenvolvimento de novos medicamentos, especialmente para áreas em que a medicina ainda não dá resposta e para doenças raras, e ter um papel mais ativo no que respeita às ameaças de Saúde Pública em que estejam envolvidos medicamentos. No que respeita ao acesso aos medicamentos, deve reforçar os mecanismos de avaliação da relação benefício/risco e de todos os mecanismos, regulatórios e científicos, necessários à avaliação científica. No que diz respeito ao último objetivo, deve, entre outras medidas, reforçar os mecanismos de monitorização pós-autorização, defender a segurança dos pacientes diminuindo o risco desnecessário associado ao consumo de medicamentos e tornar-se o principal órgão de informação dos medicamentos que avalia.

Todas estas questões foram tidas em conta pela Agência e atualmente, funcionando como uma rede de mais de 40 agências reguladoras da União Europeia e da Área Económica Europeia (EEA), desempenha um papel fundamental como agência europeia de Saúde Pública. Os peritos científicos das mais diversas áreas estão presentes

\footnotetext{
${ }^{56}$ HOEBERT, Joëlle M., [et al.] - Future of the European Union regulatory network in the context of the uptake of new medicines. British Journal of Clinical Pharmacology. 76: 1 (2013), p.1-6.

${ }^{57}$ European Medicines Agency - Implementing the European Medicines Agency's Road map to 2015: The Agency's contribution to Science, Medicines, Health. "From Vision to Reality". London: EMA, $2011 b$.
} 
através dos comités científicos, dos grupos de aconselhamento científico e dos mais diversos grupos de trabalho associados à estrutura da agência. A nível internacional a Agência estabelece relações de cooperação não só ao nível da ICH e do correspondente para os medicamentos veterinários (VICH), mas também com a OMS, com a FDA, com as autoridades japonesas, canadianas e australianas e outras regiões não-ICH, o que permite o estabelecimento de acordos internacionais e uma harmonização técnicocientífica de nível internacional.

Outra das grandes preocupações da agência tem sido ao nível da transparência e comunicação, não só entre a agência e os demais atores do circuito do medicamento, nomeadamente agências reguladoras nacionais e Indústria Farmacêutica, mas também entre a agência e os pacientes e consumidores de medicamentos, funcionando como um polo de informação de medicamentos.

Tudo isto, associado à grande contribuição da agência ao nível do aconselhamento científico prestado, fez com que a agência visse a sua atividade crescer consideravelmente ao longo do tempo, assumindo um papel cada vez mais importante não só do ponto de vista europeu, mas também do ponto de vista internacional, funcionando atualmente como um leading actor no estabelecimento de diretrizes internacionais.

\section{Fontes e Bibliografia}

ABRAHAM, John - Partial Progress: Governing the Pharmaceutical Industry and the NHS, 1948-2008. Journal of Health Politics, Policy and Law. 34: 6 (2009), p.931977.

ABRAHAM, John - The pharmaceutical industry as a political player. The Lancet. 360: novembro, 9 (2002), p.1498-1502.

BROSCHEID, Andreas; FEICK, Jürgen- Towards a European FDA? The review of European pharmaceuticals authorization. Prepared for delivery at the 2005 Meeting of the European Union Studies Association, March 31 - April 2, Austin, Tx., 2005. 
CAVACO, António C. C. - A Construção da Europa do Medicamento. Um desafio do Mercado Único. Porto: Ordem dos Farmacêuticos, 1992.

Comissão Europeia - Directorate-General Enterprise Pharmaceuticals and Cosmetics Evaluation of the operation of Community procedures for the authorisation of medicinal products. . Evaluation carried out on behalf of the European Commission by CMS Cameron McKenna and Andersen Consulting. London: 2001.

DAVIS, Courtney; ABRAHAM, John - The political dynamics of citizenship, innovation, and regulation in pharmaceutical governance. Innovation: The European Journal of Social Science Research. 25: 4 (2012), p.478-496.

DEBOYSER, Patrick - Política Europeia do Medicamento. 1as Jornadas do INFARMED. As políticas nacionais face à internacionalização. Lisboa: INFARMED, 1997.

European Commission - Evaluation of the European Medicines Agency Brussels: Evaluation carried out on behalf of the European Commission by Ernst \& Young et Associés 2010.

European Medicines Agency - Annual report 2010. London: EMA, 2011a.

European Medicines Agency - Implementing the European Medicines Agency's Road map to 2015: The Agency's contribution to Science, Medicines, Health. “From Vision to Reality”. London: EMA, 2011 b.

FEICK, Jürgen - "Marketing authorization for pharmaceuticals in the European Union. How regulators in energy, financial services, pharmaceuticals and telecoms are coming together in european networks and agencies. " In European Policy Forum. Joining-up Europe's Regulators. London, 2008. p. 35-64. 
HARRON, Dean W.G. - "Technical requirements for registration of pharmaceuticals for human use: the ICH process" In Griffin, John P. The Textbook of Pharmaceutical Medicine. . 6th Edition. Oxford: BMJ Books, 2009. p. 522-533.

HOEBERT, Joëlle M., [et al.] - Future of the European Union regulatory network in the context of the uptake of new medicines. British Journal of Clinical Pharmacology. 76: 1 (2013), p.1-6.

International Conference on Harmonisation of Technical Requirements for Registration of Pharmaceuticals for Human Use - The value and benefits of ICH to Drug Regulatory Authorities - advancing harmonization for better health. Geneva: ICH, 2010.

IVO, Rui Santos - Revisão do sistema europeu de medicamentos. Reforçar os Mecanismos de Protecção da Saúde Pública. Boletim do CIM - Centro de informação do medicamento. Ordem dos Farmacêuticos. In Revista da Ordem dos Farmacêuticos, Ano XI, nº 61: (2004), p.1-2.

JARDIM, Sara Vera - Saúde Pública made in União Europeia. Base legal habilitadora e limites da competência europeia em matéria de Saúde Pública (artigo $152^{\circ}$ do TCE). Lex Medicinae. Revista Portuguesa de Direito da Saúde. Ano 6: 11 (2009), p.67-94.

KRAPOHL, Sebastian - Credible Commitment in Non-Independent Regulatory Agencies: A Comparative Analysis of the European Agencies for Pharmaceuticals and Foodstuffs. European Law Journal. 10: 5, setembro (2004), p.518-538.

KRAPOHL, Sebastian - Thalidomide, BSE and the single market: An historicalinstitutionalist approach to regulatory regimes in the European Union. European Journal of Political Research. 46 (2007), p.25-46.

LEWIS, Graham; ABRAHAM, John - The creation of neo-liberal corporate bias in transnational medicine control: The industrial shaping and interest dynamics of the 
European regulatory state. European Journal of Political Research. 39 (2001), p.5380 .

MCKEE, Martin; MOSSIALOS, Elias - Health policy and European law: Closing the gaps. Public Health. 120 (2006), p.16-22.

PEREIRA, André Gonçalo Dias - Um direito da saúde para a europa? Debater a Europa. 2/3, janeiro/dezembro (2010), p.25-37.

PERMANAND, Govin; ALTENSTETTER, Christa - "The politics of pharmaceuticals in the European Union" In Mossialos, Elias, [et al.]. Regulating pharmaceuticals in Europe: striving for efficency, equity and quality. Berkshire: Open University Press McGraw-Hill Education, 2004. p. 38-54.

SÁENZ, Francisco Miguel Bombillar- Intervención administrativa y régimen jurídico del medicamento en la unión europea. Granada: Universidad de Granada, 2010. Tese de Doutoramento.

SOUSA, Micaela Figueira de; PITA, João Rui; PEREIRA, Ana Leonor - Farmácia e medicamentos em Portugal em meados do século XX: o papel da Comissão Reguladora dos Produtos Químicos e Farmacêuticos (1940). CEM/Cultura, Espaço \& Memória. Dossier temático "População e Saúde": 5 (2014), p.11-26.

VALVERDE, José Luís - "El estatuto jurídico del medicamento en la unión europea" In Ministerio de Sanidad y Consumo. España y Europa, hacia un ideal sanitario común. Madrid, 2002. p. 85-165.

Legislação comunitária e documentos conexos (por ordem cronológica de publicação)

\section{Tratados Europeus}


Tratado que instituiu a Comunidade Europeia do Carvão e do Aço. Paris. 1951. Disponível em http://eur-lex.europa.eu/collection/eu-law/treaties-founding.html.

Tratado que instituiu a Comunidade Económica Europeia. Roma. 1957. Ibidem.

Tratado que instituiu a Comunidade Europeia da Energia Atómica. Roma. 1957. Ibidem.

Ato Único Europeu. JO nº L169, de 29 de junho de 1987.

Tratado da União Europeia, assinado em Maastricht em 7 de fevereiro de 1992. JO no C191, de 29 de julho de 1992.

Tratado de Amesterdão que altera o Tratado da União Europeia, os Tratados que instituem as Comunidades Europeias e alguns actos relativos a esses Tratados, assinado em Amesterdão em 2 de outubro de 1997. JO n ${ }^{\circ}$ C340, de 10 de novembro de 1997.

Tratado de Lisboa que altera o Tratado da União Europeia e o Tratado que institui a Comunidade Europeia, assinado em Lisboa em 13 de dezembro de 2007. JO nº C306, de 17 de dezembro de 2007.

\section{Legislação}

Conselho - Diretiva 65/65/CEE do Conselho, de 26 de janeiro de 1965 relativa à aproximação das disposições legislativas, regulamentares e administrativas, respeitantes às especialidades farmacêuticas. JO no 369 de 09.02.1965. p. 18-22.

Conselho - Diretiva 75/318/CEE do Conselho de 20 de maio de 1975 relativa à aproximação das legislações dos Estados-membros respeitantes às normas e protocolos analíticos, tóxico-farmacológicos e clínicos em matéria de ensaios de especialidades farmacêuticas. JO n ${ }^{\circ}$ L147 de 09.06.1975, p. 1. p. 80-91. 
Conselho - Diretiva 75/319/CEE do Conselho, de 20 de maio de 1975 relativa á aproximação das disposições legislativas, regulamentares e administrativas respeitantes às especialidades farmacêuticas. JO nº L147 de 09.06.1975, p. 13. p. 92-101.

Conselho - Decisão 75/320/CEE do Conselho, de 20 de maio de 1975 que institui um Comité Farmacêutico.

Conselho - Diretiva 83/570/CEE do Conselho, de 26 de outubro de 1983 de modificação das Diretivas 65/65/CEE, 75/318/CEE e 75/319/CEE relativas à aproximação das disposições legislativas, regulamentares e administrativas sobre especialidades farmacêuticas. JO n ${ }^{\circ}$ L332, de 28.11.1983. p. 205-214.

Conselho - Diretiva 87/22/CEE do Conselho, de 22 de dezembro de 1986 relativa à aproximação das medidas nacionais respeitantes à colocação no mercado dos medicamentos de alta tecnologia, nomeadamente dos resultantes da biotecnologia. JO $n^{\circ} \mathrm{L} 15$, de 17.01.1987. p. 38-41.

Conselho - Diretiva 89/342/CEE do Conselho, de 3 de maio de 1989 que alarga o âmbito de aplicação das Diretivas 65/65/CEE e 75/319/CEE e que estabelecem disposições complementares para os medicamentos imunológicos que consistam em vacinas, toxinas ou soros e alergénios. JO nº L142 de 25.05.1989. p.14.

Conselho - Diretiva 89/343/CEE do Conselho, de 3 de maio de 1989 que amplia o âmbito de aplicação das Diretivas 65/65/CEE e 75/319/CEE e prevê disposições complementares para os medicamnetos radiofarmacêuticos. JO nº142, de 25.05.1989. p. 16-18.

Conselho - Diretiva 89/381/CEE do Conselho, de 14 de junho de 1989 que alarga o âmbito de aplicação das Diretivas 65/65/CEE e 75/319/CEE relativas à aproximação das disposições legislativas, regulamentares e administrativas respeitantes às especialidades farmacêuticas e que prevê disposições especiais para os medicamentos derivados do sangue ou plasma humanos. JO nº L181 de 28.06.1989. p. 44-46. 
Conselho - Regulamento (CEE) No 2309/93 do Conselho de 22 de julho de 1993 que estabelece procedimentos comunitários de autorização e fiscalização de medicamentos de uso humano e veterinário e institui uma Agência Europeia de Avaliação de Medicamentos. JO L214, de 24.08.1993. p. 1-21.

Conselho - Diretiva 93/39/CEE do Conselho de 14 de junho de 1993 que altera as Diretivas 65/65/CEE, 75/318/CEE e 75/319/CEE respeitantes às especialidades farmacêuticas. JO n ${ }^{\circ}$ L214 de 24 de agosto de 1993. p. 22-30.

Conselho - Diretiva 93/41/CEE do Conselho de 14 de junho de 1993 que revoga a Diretiva 87/22/CEE, relativa à aproximação das medidas nacionais respeitantes à colocação no mercado dos medicamentos de alta tecnologia, nomeadamente dos resultantes da biotecnologia. JO n ${ }^{\circ}$ L214, de 24 de agosto de 1993. p. 40.

Parlamento Europeu e Conselho - Diretiva 2001/83/CE do Parlamento Europeu e do Conselho, de 6 de novembro de 2001 que estabelece um código comunitário relativo aos medicamentos para uso humano. JO n ${ }^{\circ}$ L311 de 28.11.2001. p. 67-128.

Parlamento Europeu e Conselho - Diretiva 2004/27/CE do Parlamento Europeu e do Conselho de 31 de março de 2004 que altera a Diretiva 2001/83/CE que estabelece um código comunitário relativo aos medicamentos para uso humano. JO nL136 de 30.04.2004. p. 34-57.

Parlamento Europeu e Conselho - Diretiva 2004/28/CE do Parlamento Europeu e do Conselho de 31 de março de 2004 que altera a Diretiva 2001/82/CE que estabelece um Código Comunitário relativo aos Medicamentos para Uso Veterinário. JO L136 de 30.04.2004. p. 58-84.

Parlamento Europeu e Conselho - Diretiva 2004/24/CE do Parlamento Europeu e do Conselho de 31 de março de 2004 que altera, em relação aos medicamentos tradicionais à base de plantas, a Diretiva 2001/83/CE que estabelece um Código Comunitário relativo aos Medicamentos para Uso Humano. JO L136 de 30.04.2004. p. 85-90 
Parlamento Europeu e Conselho - Regulamento (CE) nº 726/2004 do Parlamento Europeu e do Conselho de 31 de março de 2004 que estabelece procedimentos comunitários de autorização e de físcalização de medicamentos para uso humano e veterinário e que institui uma Agência Europeia de Medicamentos. JO nº L136, de 30.04.2004. p. 1-51.

\section{Documentos Preparatórios}

Commission of the European Communities - COM (79) 59 Final. First Commission report to the Council on the functioning of the Committee for Proprietary Medicinal Products and its impact on the development of intra-Community trade.

Comissão Europeia - COM (90) 283 final. JO nº C330, de 31 de dezembro de 1990.

Commission of the European Communities - COM (2001) 606 Final. Report from the Commission on the experience acquired as a result of the operation of the procedures for granting marketing authorisations for medicinal products laid down in Regulation (EEC) $\mathrm{N}^{\circ} 2309 / 93$, in chapter III of directive 75/319/EEC and chapter IV of directive 81/851/EEC. Report on the basis of Article 71 of Regulation (EEC) No 2309/93.

Comissão Europeia - COM (2001) 404 final.

Artigo Recebido a 31 de outubro de 2015 | Aceite a 11 de março de 2016 